\title{
Synergistic Antileukemic Activity of Carnosic Acid-Rich Rosemary Extract and the 19-nor Gemini Vitamin D Analogue in a Mouse Model of Systemic Acute Myeloid Leukemia
}

\author{
Ayelet Shabtay $^{\mathrm{a}}$ Hagar Sharabani ${ }^{\mathrm{a}}$ Zeev Barvish $^{\mathrm{b}}$ Michael Kafka ${ }^{\mathrm{c}}$ \\ Doron Amichay $^{d}$ Joseph Levy ${ }^{a}$ Yoav Sharonia Milan R. Uskokovic ${ }^{\mathrm{e}}$ \\ George P. Studzinskif ${ }^{f}$ Michael Danilenko ${ }^{a}$
}

Departments of a Clinical Biochemistry and birology and Molecular Genetics, Ben-Gurion University of the Negev, and Laboratories of ${ }^{\mathrm{C}}$ Hematology and ${ }^{\mathrm{d}}$ Biochemistry, Soroka Medical Center, Beer-Sheva, Israel;

eBioXell, Inc., Nutley, N.J., and f Department of Pathology and Laboratory Medicine, University of Medicine and Dentistry of New Jersey-New Jersey Medical School, Newark, N.J., USA

\section{Key Words}

Acute myeloid leukemia • Carnosic acid • Differentiation • Hypercalcemia - Rosemary extract • Syngeneic mouse model $\cdot$ Vitamin D

\begin{abstract}
Objective: Differentiation therapy with the hormonal form of vitamin $D, 1 \alpha, 25$-dihydroxyvitamin $D_{3}\left(1,25 D_{3}\right)$, is a promising approach to treatment of acute myeloid leukemia (AML); however, 1,25D 3 induces hypercalcemia at pharmacologically active doses. We investigated the in vitro and in vivo antileukemic efficacy of combined treatment with non-toxic doses of a low-calcemic $1,25 \mathrm{D}_{3}$ analogue, 1,25-dihydroxy21(3-hydroxy-3-methyl-butyl)-19-nor-cholecalciferol (19nor-Gemini; Ro27-5646), and rosemary plant agents in a mouse model of AML. Methods: Proliferation and differentiation of WEHI-3B D- (WEHI) murine myelomonocytic leukemia cells in vitro were determined by standard assays. Reactive oxygen species, glutathione and protein expression levels were measured by flow cytometry, enzymatic assay and Western blotting, respectively. Systemic AML was developed by intravenous injection of WEHI cells in syngeneic
\end{abstract}

Balb/c mice. Results: 19-nor-Gemini had a higher potency than its parent compounds, Gemini (Ro27-2310) and $1,25 D_{3}$, in the induction of differentiation $\left(\mathrm{EC}_{50}=0.059 \pm 0.011\right.$, $0.275 \pm 0.093$ and $0.652 \pm 0.085 \mathrm{nM}$, respectively) and growth arrest $\left(\mathrm{IC}_{50}=0.072 \pm 0.018,0.165 \pm 0.061\right.$ and 0.895 $\pm 0.144 \mathrm{nM}$, respectively) in WEHI cells in vitro, and lower in vivo toxicity. Combined treatment of leukemia-bearing mice with 19-nor-Gemini (injected intraperitoneally) and standardized rosemary extract (mixed with food) resulted in a synergistic increase in survival (from $42.2 \pm 2.5$ days in untreated mice to $66.5 \pm 4.2$ days, $n=3$ ) and normalization of white blood cell and differential counts. This was consistent with strong cooperative antiproliferative and differentiation effects of low concentrations of 19-nor-Gemini or $1,25 D_{3}$ combined with rosemary extract or its major polyphenolic component, carnosic acid, as well as with the antioxidant action of rosemary agents and vitamin D derivatives in WEHI cell cultures. Conclusion: Combined effectiveness of $1,25 \mathrm{D}_{3}$ analogues and rosemary agents against mouse AML warrants further exploration of this therapeutic approach in translational models of human leukemia.

Copyright $\odot 2008$ S. Karger AG, Basel

Dr. Michael Danilenko, PhD

Department of Clinical Biochemistry, Faculty of Health Sciences

Ben-Gurion University of the Negev, PO Box 653

Beer-Sheva 84105 (Israel)

Tel. +972 8647 9979, Fax +972 8640 3177, E-Mail misha@bgu.ac.il 


\section{Introduction}

A characteristic feature of acute myeloid leukemia (AML) is a defect in the capacity of myeloid progenitors to mature into non-replicating adult cells. Despite recent advancements in our understanding of the etiology and pathophysiology of AML, therapy of this disorder remains a tremendous challenge and it continues to have the lowest survival rate of all leukemias. One of the major obstacles in the management of AML is that the current chemotherapeutic drugs are highly toxic and poorly tolerated, particularly by older patients [1]. Differentiation therapy is a relatively novel and targeted approach to AML treatment, based on the induction of leukemic cells to mature beyond the differentiation block, and thus to restore the normal cellular phenotype without cytodestruction. The physiologically active form of vitamin $\mathrm{D}_{3}$, $1 \alpha, 25$-dihydroxyvitamin $\mathrm{D}_{3}\left(1,25 \mathrm{D}_{3}\right)$, has the ability to induce differentiation, growth arrest and apoptosis in a wide variety of cancer cell types $[2,3]$. However, the hypercalcemic effect at pharmacologically effective doses has greatly limited its clinical usefulness. Attempts to circumvent this adverse reaction have included the use of high intermittent doses of $1,25 \mathrm{D}_{3}$ that can be administered to patients with prostate and other cancers without apparent toxicity [4]. Further, a number of vitamin D analogues with lower calcemic effects have been synthesized, which retain the differentiation and antiproliferative activities of the parent compound in myeloid leukemia cells and other cancer cell lines [5-8].

One of the important principles in integrative cancer treatment, which is used in conventional chemotherapy, is that single agents, though likely to show modest activity when used alone, display synergistic effects when combined with other agents. Thus, most chemotherapy regimens employ multiple agents with different modes of action. For example, standard treatment of AML generally includes a synthetic pyrimidine nucleoside cytarabine (Ara-C), which functions as an antimetabolite and DNA polymerase inhibitor, in combination with an anthracycline agent (idarubicin or daunorubicin), which acts as topoisomerase II inhibitor and DNA intercalator [1]. In analogy, the anticancer effects of combinations of vitamin $\mathrm{D}$ derivatives (deltanoids) with other agents have been extensively studied in cultures of leukemic cells and other cancer cell types [9-12], animal models of cancer $[13,14]$ and clinical trials [15-17]. These studies are especially important since combination treatment may allow lower doses of deltanoids, thereby further limiting calcemic toxicity of these compounds.
Of the various agents tested in combination with deltanoids, natural plant-derived compounds, such as polyphenolic antioxidants, represent a group of relatively safe compounds which constitute a part of the diet or herbal medicinal remedies. For example, several plant polyphenolic antioxidants, e.g. curcumin derived from turmeric and silibinin from milk thistle, have been shown to markedly potentiate the differentiation effects of $1,25 \mathrm{D}_{3}$ in leukemic cell cultures [18-20]. We have recently shown that carnosic acid, the major polyphenolic antioxidant of the rosemary plant (Rosmarinus officinalis), synergistically potentiates the differentiating and antiproliferative effects of $1,25 \mathrm{D}_{3}$ and its low-calcemic analogue, 1,25-dihydroxy-16-ene-5,6-trans-cholecalciferol (Ro25-4020) in human myeloblastic (HL60) and promonocytic (U937) leukemia cells as well as WEHI-3B D- (WEHI) murine myelomonocytic leukemia cells [14, 20-23]. Similar potentiating effects in both human and murine leukemic cells were obtained with the ethanolic extract of rosemary leaves containing $\sim 30 \%$ carnosic acid [14].

In this study, we employed a recently established syngeneic mouse model of systemic AML to explore if under clinically relevant experimental conditions combinations of a low-calcemic vitamin D analogue of the Gemini family [24], 1,25-dihydroxy-21(3-hydroxy-3-methyl-butyl)19-nor-cholecalciferol (19-nor-Gemini; Ro27-5646), and polyphenol-rich rosemary preparations have therapeutic potential in human-like disseminated leukemia. Indeed, the combined treatment with rosemary extract and this deltanoid produced a dramatic prolongation of life in our systemic AML model. Considering the essential similarity of WEHI and human leukemia cells with respect to the enhanced antiproliferative and differentiating action of rosemary polyphenol-deltanoid combinations [14], our in vivo data provide the basis for initial steps towards human translational research of such combinations in myeloid leukemia and eventually other types of cancer.

\section{Materials and Methods}

\section{Materials}

The deltanoids, 1,25 $\mathrm{D}_{3}$, 1,25-dihydroxy-21-(3-hydroxy-3methylbutyl)-cholecalciferol (Gemini) and 19-nor Gemini, were prepared at BioXell, Nutley, N.J., USA. Carnosic acid was purchased from Alexis Biochemicals (Läufelfingen, Switzerland). A dried ethanolic extract of rosemary leaves (rosemary extract; lot No. LR-06-1-3/A) containing 33.9\% (w/w) carnosic acid and 5.16\% (w/w) carnosol as the major polyphenols, was provided by LycoRed Natural Products Industries (Beer Sheva, Israel). Fluorescein isothiocyanate (FITC)-conjugated rat anti-mouse F4/80 antibody was purchased from eBioscience (San Diego, Calif., USA). 
Other reagents were obtained from Sigma (St. Louis, Mo., USA). Stock solutions of carnosic acid $(10 \mathrm{mM})$, rosemary extract $(10 \mathrm{mM}$ equivalent of carnosic acid), $1,25 \mathrm{D}_{3}$, Gemini and 19-nor-Gemini $(0.2-1.0 \mathrm{mM})$ were prepared in absolute ethanol. The precise concentrations of $1,25 \mathrm{D}_{3}$ and Gemini analogues in stock solutions were verified spectrophotometrically at $264 \mathrm{~nm}(\varepsilon=19,000)$ and $262 \mathrm{~nm}(\varepsilon=24,960)$, respectively [14, 25].

\section{WEHI-3B D-Cell Culture and Treatments}

WEHI-3B D- murine myelomonocytic leukemia cells were obtained from Dr. A. Sartorelli (Yale University School of Medicine, New Haven, Conn., USA). Cells were maintained at $37^{\circ} \mathrm{C}$ in $\mathrm{Mc}-$ Coy's 5 a medium supplemented with heat-inactivated $10 \%$ fetal calf serum and $1 \%$ penicillin-streptomycin (Biological Industries, Beit Haemek, Israel) in $95 \%$ air $/ 5 \% \mathrm{CO}_{2}$. For in vitro experiments, cells were seeded in 6 -well culture plates at $5.0 \times 10^{3}$ cells $/ \mathrm{ml}$ or $2.5 \times 10^{4}$ cells $/ \mathrm{ml}$ and incubated with test agents for 96 or $48 \mathrm{~h}$, respectively. Control samples were treated with vehicle $(0.2 \%$ ethanol), which did not significantly affect the parameters tested.

\section{Proliferation and Differentiation Assays}

Cell number and viability were estimated on the basis of the trypan blue exclusion assay by counting cells in a Vi-Cell XR cell viability analyzer (Beckman Coulter, Miami, Fla., USA). The expression of F4/80 (murine monocyte/macrophage differentiation marker) was assessed by flow cytometry in $1 \times 10^{6}$ cells labeled with $0.3 \mu$ g anti-F4/80-FITC, as described previously [14]. Analysis was performed on a Cytomics FC500 flow cytometer equipped with CXP software (Beckman Coulter). Cell differentiation was also measured by 12-O-tetradecanoyl-phorbol-13-acetate (TPA)stimulated superoxide production using the nitroblue tetrazolium reduction assay, and by cytochemical determination of the cytoplasmic enzyme monocyte-specific esterase (MSE) activity, as described previously $[14,22]$.

\section{Measurement of Intracellular Reactive Oxygen Species by Flow Cytometry}

Determination of intracellular reactive oxygen species (ROS) was performed as described previously [21] using the oxidationsensitive fluorescent probe $2^{\prime}, 7^{\prime}$-dichlorofluorescein diacetate (DCFH-DA). Intracellular peroxides oxidize this probe to a highly fluorescent compound DCF. Cells $\left(5 \times 10^{5}\right)$ were harvested, washed with HEPES-buffered HBSS and loaded with $5 \mu \mathrm{M} \mathrm{DCFH}-$ $\mathrm{DA}$ for $15 \mathrm{~min}$ at $37^{\circ} \mathrm{C}$ in a shaking water bath. The green fluorescence intensity was then analyzed on a Cytomics FC500 flow cytometer. For each analysis 10,000 events were recorded.

\section{Total Cellular Glutathione Assay}

Cells $\left(2 \times 10^{6}\right)$ were collected, washed with ice-cold PBS and resuspended in $200 \mu \mathrm{l} 5 \% 5$-sulfosalicylic acid. After $15 \mathrm{~min}$ on ice with intermittent vortexing, the suspension was centrifuged at $16,000 \mathrm{~g}$ for $5 \mathrm{~min}$ to remove protein precipitates. Total glutathione was determined in the supernatants by the glutathione reductase recycling assay as described previously [21].

\section{Preparation of Whole Cell Extracts and Immunoblotting}

Whole cell extracts were prepared as described previously [22]. Briefly, cells were solubilized in $1 \times$ lysis buffer (Cell Signaling, Danvers, Mass., USA) and mixed with SDS sample buffer. Protein concentration was determined by a Bio-Rad protein assay using bovine serum albumin as the standard. Samples $(50 \mu \mathrm{g}$ of protein) were subjected to SDS-PAGE on a $10 \%$ gel and transferred to nitrocellulose membranes (Whatman, Dassel, Germany). The membranes were blocked with $5 \%$ defatted milk, blotted overnight with goat anti-NQO1 (C-19) and then with a horseradish-linked secondary antibody for $1 \mathrm{~h}$. The protein bands were visualized using a Western Lightning ${ }^{\circledR}$ Chemiluminescence Reagent Plus (PerkinElmer Life Sciences, Boston, Mass., USA). The blots were stripped and successively reprobed for the constitutively present protein, calreticulin, which served as the loading control. The optical density (OD) of each band was quantitated using an ImageMaster VDS-CL imaging system (Amersham Pharmacia Biotech, Piscataway, N.J., USA).

\section{Experimental Animals}

Experiments were carried out in the animal facility of the Soroka University Medical Center (Beer-Sheva, Israel) in accordance with the Ben-Gurion University Institutional Animal Care and Use Committee-approved protocol. Six-to 8-week-old female $\mathrm{Balb} / \mathrm{c}$ mice were purchased from Harlan Laboratories (Jerusalem, Israel). Mice were housed in sterilized cages and provided with autoclaved water and a standard powdered rodent diet ad libitum. Experimental protocols were initiated following a 7-day acclimatization period.

\section{Administration of Vitamin D Derivatives}

Stock solutions of $1,25 \mathrm{D}_{3}$, Gemini and 19-nor-Gemini in ethanol were diluted in ice-cold sterile PBS. The vehicle contained PBS and appropriate concentrations of ethanol. The final ethanol concentration in the injection volume did not exceed $0.1 \%$. Deltanoids or vehicle were injected intraperitoneally in $100 \mu \mathrm{l} \mathrm{PBS}$, three times a week (Sunday, Tuesday and Thursday), as described previously [14].

\section{Cell Inoculation and Treatment Protocol}

Mice were inoculated in the lateral tail vein with $2 \times 10^{6} \mathrm{WEHI}$ cells suspended in $100 \mu \mathrm{l}$ sterile PBS and randomly assigned to four groups (6 or 10 animals per group; see Statistical Analyses). All treatments began 7 days after inoculation. The control group (group 1) received intraperitoneal injections of the deltanoid vehicle (0.05\% ethanol in PBS, 3 times per week); group 2 received intraperitoneal injections of $0.1 \mu \mathrm{g} 19$-nor-Gemini in $0.05 \%$ ethanol/PBS, 3 times per week; group 3 received $4 \%$ (w/w) rosemary extract mixed with food, ad libitum, and the combination group (group 4) was treated with both $0.1 \mu \mathrm{g} 19$-nor-Gemini (3 times per week) and $4 \%(\mathrm{w} / \mathrm{w})$ rosemary extract mixed with food.

\section{Animal Survival Assay}

The control and treated leukemia-bearing mice were monitored for up to 15 weeks. Animal body weight, appearance and behavior were assessed daily. To determine white blood cell (WBC) number and differential counts, peripheral blood samples were collected weekly from the retro-orbital sinus under isoflurane anesthesia. Moribund animals were humanely sacrificed by the institutionally approved method ( $\mathrm{CO}_{2}$ suffocation). The bone marrow was removed from both femurs, smeared on glass slides and subjected to cytological analysis. Overall animal survival was estimated by the Kaplan-Meier analysis [26]. All hematological analyses were performed using standard procedures in the Hematology Laboratory of the Soroka University Medical Center. 
Evaluation of in vivo Toxicity

Toxicity of deltanoids and rosemary extract was estimated in pilot experiments in healthy mice by clinical measures (weight loss, changes in appearance and behavior, lethargy and death) and blood chemistry tests (serum calcium, albumin, total bilirubin, creatinine and urea), as described previously [14]. In animal survival assays, blood chemistry was monitored every 2 weeks in the retro-orbital samples from 5 mice randomly selected from each treatment group. The biochemical tests were performed by automatic analysis in the Biochemistry Laboratory of the Soroka University Medical Center.

\section{Statistical Analyses}

In vitro experiments were repeated at least three times. Doseresponse curves for deltanoids in cell proliferation and differentiation assays were generated by nonlinear regression analysis. Two compounds (A and B) were considered to show synergy in the particular experiment if the effect of their combination $(A B)$ was larger than the sum of their individual effects $(A B>A+B)$, the data being compared after subtraction of the respective control values from A, B and AB [22]. Statistically significant differences between different treatments were estimated by unpaired, two-tailed Student's t test. Animal survival experiments were repeated three times in groups of 6 mice (two experiments) and 10 mice (one experiment). The log-rank (Mantel-Cox) test was used to determine significant differences between survival curves generated by the Kaplan-Meier method. All statistical analyses were performed using a GraphPad Prism 3.0 program (GraphPad Software, San Diego, Calif., USA). p $<0.05$ was considered statistically significant.

\section{Results}

\section{9-nor-Gemini Is a More Potent and Less Toxic}

Deltanoid than Its Parent Compounds, Gemini or

$1,25 \mathrm{D}_{3}$

In order to select a potent and low-toxic deltanoid for the in vivo study, we first compared the differentiation and antiproliferative effects of $1,25 \mathrm{D}_{3}$ and its two analogues of the Gemini series with two identical side chains at carbon 20 [24], Gemini and its 19-nor derivative 19nor-Gemini (fig. 1), in WEHI cell culture. Cells were grown in the presence of increasing concentrations of either compound for $96 \mathrm{~h}$ followed by measurement of a general myeloid differentiation marker (superoxide production) and cell proliferation. As shown in figure $2 a, b$, the order of potencies was: 19 -nor-Gemini $>$ Gemini $>$ $1,25 \mathrm{D}_{3}$ for both the induction of differentiation $\left(\mathrm{EC}_{50}=\right.$ $0.059 \pm 0.011,0.275 \pm 0.093$ and $0.652 \pm 0.085 \mathrm{nM}$, respectively) and cell growth inhibition $\left(\mathrm{IC}_{50}=0.072 \pm\right.$ $0.018,0.165 \pm 0.061$ and $0.895 \pm 0.144 \mathrm{nM}$, respectively). No significant decrease in cell viability compared to vehicle-treated control cells ( $\geq 95 \%$ viable cells) was ob-
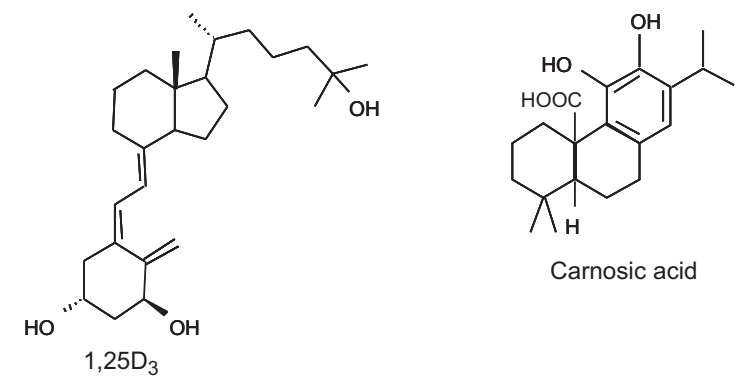

Carnosic acid

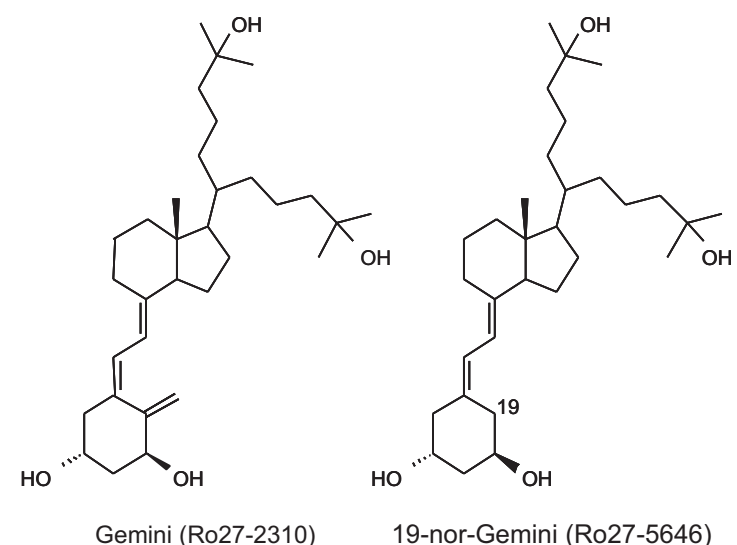

Fig. 1. Structures of the rosemary polyphenol, carnosic acid and deltanoids used in this study. Carnosic acid, the polyphenolic diterpene with antioxidant properties derived from the plant $R$. officinalis L. (rosemary). $1,25 \mathrm{D}_{3}=$ Parent vitamin $\mathrm{D}$ compound, $1 \alpha, 25$-dihydroxyvitamin $\mathrm{D}_{3}$; Gemini $($ Ro27-2310) $=$ the vitamin $\mathrm{D}$ analogue which contains two side chains, combining a C-20normal with a C-20-epi side chain [1,25-dihydroxy-21-(3-hydroxy-3-methylbutyl)-cholecalciferol]; 19-nor Gemini (Ro27$5646)=$ its derivative with deletion of C-19 [1,25-dihydroxy-21(3hydroxy-3-methyl-butyl)-19-nor-cholecalciferol].

served even at the highest concentrations of deltanoids used (data not shown).

Preparatory to the in vivo testing, we established in a pilot experiment that the maximal tolerated dose for intraperitoneal 19-nor-Gemini in healthy mice was $0.1 \mu \mathrm{g} /$ mouse, i.e. approximately $5 \mu \mathrm{g} / \mathrm{kg}$ (data not shown). To directly compare the calcemic effects of Gemini, 19-norGemini and $1,25 \mathrm{D}_{3}$, four groups of mice were intraperitoneally injected with vehicle (control) or deltanoids at an equal dose of $0.1 \mu \mathrm{g} / \mathrm{mouse}$, for 4 weeks. As shown in figure $2 \mathrm{c}$, mice that received 19-nor-Gemini had borderline serum calcium levels which did not significantly exceed the normal values for Balb/c mice (8.5-10.5 mg/dl). Fur- 


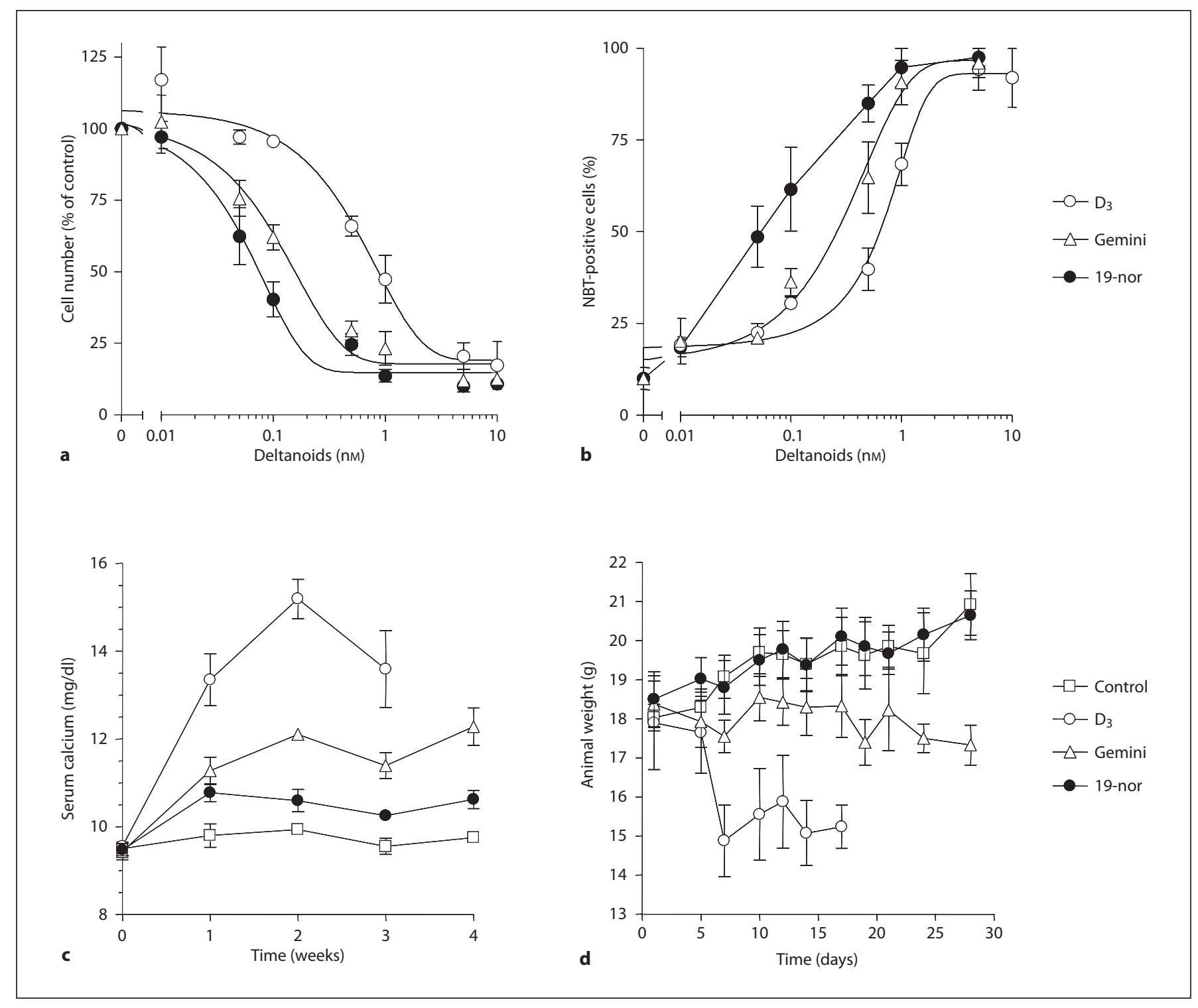

Fig. 2. 19-nor-Gemini is a more potent antiproliferative and differentiation agent than $1,25 \mathrm{D}_{3}$ or Ro27-2310, with lower calcemic activity. a, b WEHI cells $\left(5 \times 10^{3} / \mathrm{ml}\right)$ were incubated with $1,25 \mathrm{D}_{3}$ $\left(\mathrm{D}_{3}\right)$, Gemini or 19-nor-Gemini (19-nor) for $96 \mathrm{~h}$. Means \pm SE of at least three independent experiments performed in duplicate. a Viable cell counts. The data are expressed as percent of cell numbers in control cultures incubated with vehicle alone $(0.1 \%$ ethanol). The average control cell number at $96 \mathrm{~h}$ was $624,000 \pm$ 34,000 cells/ml. b TPA $(2 \mu \mathrm{M})$-stimulated nitroblue tetrazolium
(NBT) reduction (myeloid differentiation marker). The percentage of cells containing black formazan deposits was evaluated by counting 200 cells. c, d Effects of deltanoids on serum calcium and animal weight gain. Healthy Balb/c mice were intraperitoneally injected with $1,25 \mathrm{D}_{3}$, Gemini, 19 -nor (all at $0.1 \mu \mathrm{g}$ ) or vehicle ( $0.1 \%$ ethanol), 3 times per week. c Serum calcium levels were measured weekly. $\mathbf{d}$ Mice from the experiment shown in c were weighed 3 times per week. Means \pm SE of one experiment performed in groups of 10 animals. thermore, the body weight gain of the 19-nor-Geminiinjected animals was not significantly different from that of the control group (fig. $2 \mathrm{~d}$ ). In contrast, animals treated with $0.1 \mu \mathrm{g} 1,25 \mathrm{D}_{3}$ showed severe hypercalcemia (fig. $2 \mathrm{c}$ ) and dramatic weight loss (fig. 2d), and were sacrificed during week 3 due to their moribund state. Gemini demonstrated intermediate toxicity (fig. 2c, d). On the basis of the above data, 19-nor-Gemini was chosen for the further in vitro and in vivo experiments as the most effective and less toxic of the three tested deltanoids. 


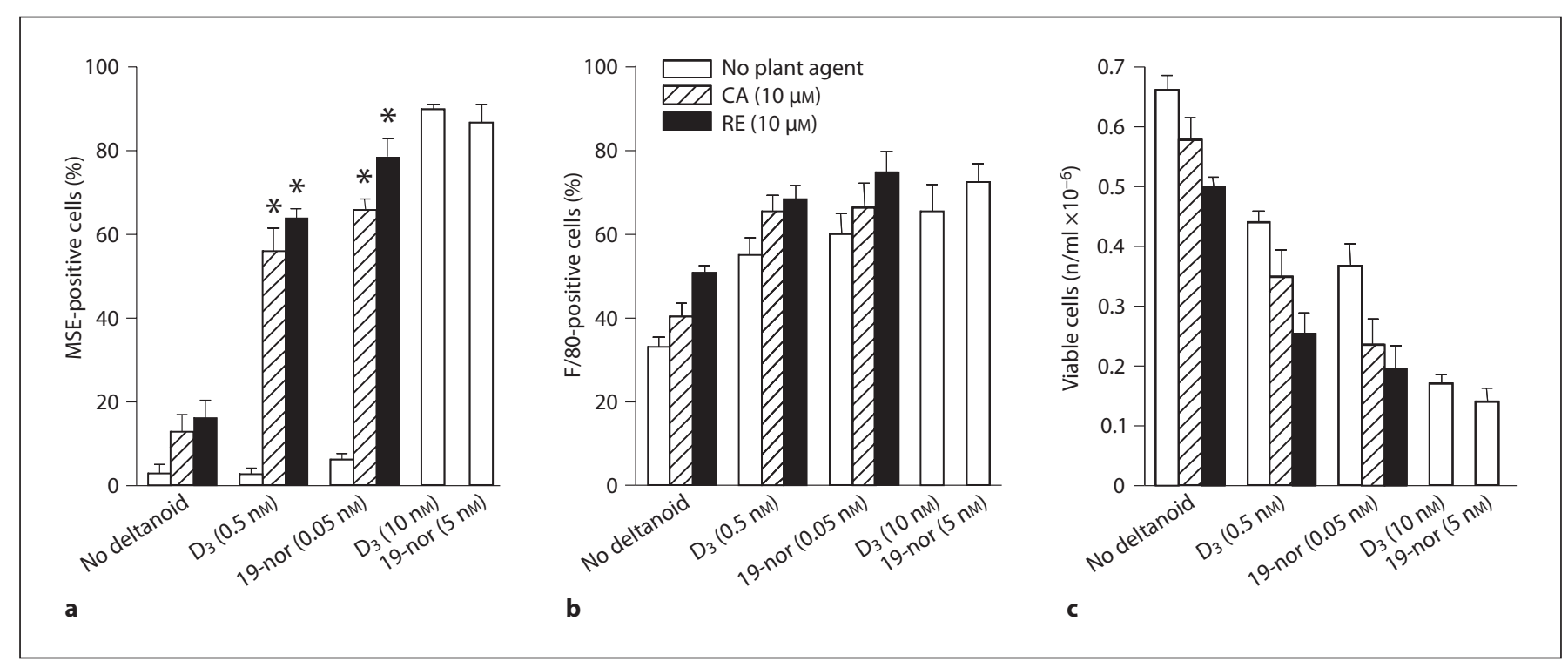

Fig. 3. Carnosic acid (CA) and rosemary extract (RE) cooperate with $1,25 \mathrm{D}_{3}\left(\mathrm{D}_{3}\right)$ and 19-nor-Gemini (19-nor) in the induction of differentiation $(\mathbf{a}, \mathbf{b})$ and inhibition of proliferation (c) in WEHI cells. Cells $\left(5 \times 10^{3} / \mathrm{ml}\right)$ were incubated with the indicated compounds for 96 h. Differentiation was assessed by MSE (a) and
F4/80 (b) assays. c Viable cell counts. Means \pm SE of four to seven independent experiments performed in duplicate. Synergistic effects of the deltanoid-carnosic acid and deltanoid-rosemary extract combinations on MSE expression were statistically significant $\left({ }^{*} \mathrm{p}<0.001\right)$.
19-nor-Gemini and Rosemary Preparations

Cooperate in the Induction of Differentiation and

Inhibition of Proliferation in WEHI Cells

The ability of 19-nor-Gemini to cooperate with rosemary preparations in the differentiation of WEHI cells was examined by the expression of specific monocyte/ macrophage differentiation markers (MSE and F4/80). $1,25 \mathrm{D}_{3}$ was used as the positive control. Control cells and those treated with single agents, such as approximately isoeffective concentrations of $1,25 \mathrm{D}_{3}$ and 19 -nor-Gemini (0.5 and $0.05 \mathrm{nM}$, respectively; fig. $2 \mathrm{a}, \mathrm{b}$ ) and $10 \mu \mathrm{M}$ carnosic acid or an equivalent concentration of rosemary extract, exhibited low MSE levels (fig. 3a). However, the combined treatments resulted in a marked synergistic increase in MSE expression. F4/80 marker levels in control WEHI cells were slightly above $30 \%$ and were further elevated by single agents, whereas the combinations produced nearly additive effects (fig. 3b). The combined treatments did not produce significant cytotoxicity (cells retained $92 \pm 5 \%$ viabilityunderallexperimental conditions; data not shown). However, at least an additive substantial growth-inhibitory effect was observed (fig. 3c). Rosemary extract, either alone or in combination with deltanoids, was slightly more potent than carnosic acid in both cell differentiation and growth assays (fig. 3). It is possible that minor components of rosemary extract, e.g. carnosol, can contribute to the biological effects of the extract along with carnosic acid. Importantly, the combinations of deltanoids at low concentrations with rosemary agents were almost as effective as much higher doses of 19-nor-Gemini ( $5 \mathrm{nM})$ or $1,25 \mathrm{D}_{3}(10 \mathrm{nM}$ ) alone (fig. 3) which exhibited maximal effects in dose-response tests (fig. 2a, b).

\section{Antioxidant Effects of Rosemary-Derived Agents and \\ Deltanoids in WEHI Cells}

Rosemary extract and purified polyphenols demonstrate strong antioxidant effects in various biologic systems [27]. We therefore investigated whether cooperative differentiation and antiproliferative effects of rosemary agents and deltanoids are associated with changes in the cellular redox state. As shown in figure 4a, WEHI cells incubated with carnosic acid or rosemary extract alone for $48 \mathrm{~h}$ displayed lower intracellular ROS levels than control cells, as indicated by a lower DCF fluorescence intensity. Interestingly, 1,25D and Ro27-5646 alone, irrespective of the concentration applied, produced a similar antioxidant effect.Combined treatmentsdid notdemonstrate cooperative reduction in ROS levels although the combinations containing carnosic acid had stronger antioxidant effects than those containing rosemary extract (fig. 4a). 
Fig. 4. Antioxidant effects of rosemary-derived agents and deltanoids in WEHI cells. Cells $\left(2.5 \times 10^{4} / \mathrm{ml}\right)$ were incubated with carnosic acid (CA), rosemary extract (RE), $1,25 \mathrm{D}_{3}\left(\mathrm{D}_{3}\right)$, 19-nor Gemini (19-nor) or their combinations for $48 \mathrm{~h}$. a Intracellular levels of ROS determined by DCF fluorescence. b Total cellular glutathione content. Means \pm SE of four independent experiments performed in duplicate.

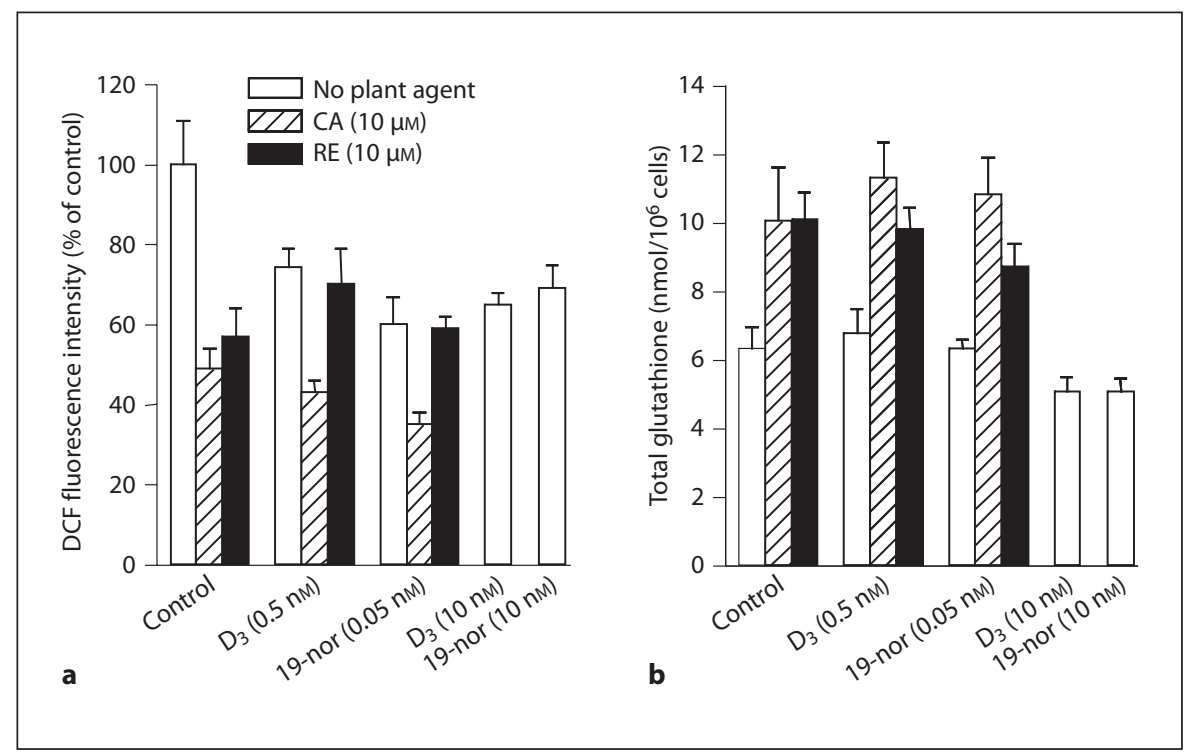

The levels of glutathione, the major cellular antioxidant, were elevated by carnosic acid and rosemary extract, but not by deltanoids while no appreciable cooperativity between the two types of agents was observed (fig. 4b). Further, we found that cell treatment with both the rosemary agents and deltanoids resulted in the induction of NADP $(\mathrm{H})$-quinone oxireductase (fig. 5), the antioxidant and phase II detoxifying enzyme known to be induced by various phytochemicals via activation of the antioxidant response element transcription system [28]. In contrast to the lack of cooperativity in the reduction in ROS levels and glutathione elevation, significant synergistic effects of drug combinations on $\mathrm{NADP}(\mathrm{H})$-quinone oxireductase induction were observed (fig. 5). Taken together, these data suggest that rosemary agents and deltanoids may affect the cellular redox status by distinct mechanisms and can cooperate at least in some of the redox-regulating pathways, leading to the establishment of reducing conditions within the cell.

\section{Establishment of a Syngeneic Mouse Model of}

Systemic AML

We adapted a syngeneic mouse model of systemic AML in which a disseminated disease was initiated by the injection of WEHI cells into the lateral tail vein [29]. $\mathrm{Balb} / \mathrm{c}$ mice injected with $2 \times 10^{6}$ cells i.v. presented clinical symptoms of AML, such as loss of appetite and apathy, which appeared with a significant delay of 25-35 days after inoculation. Within $2-4$ days after appearance of these first symptoms, the animals became moribund

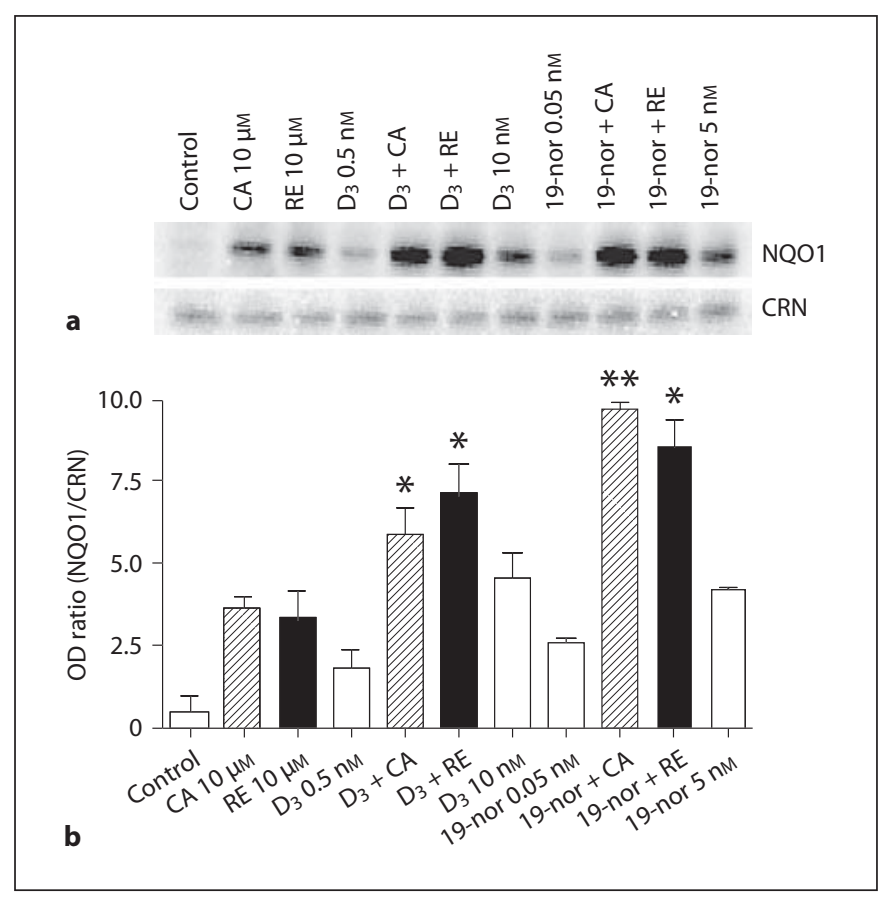

Fig. 5. Induction of $\mathrm{NADP}(\mathrm{H})$-quinone oxireductase (NQO1) by rosemary-derived agents and deltanoids in WEHI cells. Cells (2.5 $\times 10^{4} / \mathrm{ml}$ ) were incubated for $48 \mathrm{~h}$ with carnosic acid (CA), rosemary extract (RE), $1,25 \mathrm{D}_{3}\left(\mathrm{D}_{3}\right), 19$-nor Gemini (19-nor) or their combinations. a NQO1 protein levels. Membranes were reblotted for calreticulin (CRN) to demonstrate similar protein loading. b Quantitative representation of NQO1 protein expression. Average OD ratios (NQO1 vs. CRN) of three similar experiments are shown (means $\pm \mathrm{SE}$ ). Statistically significant differences in synergistic effects of the deltanoid/carnosic acid and deltanoid/rosemary extract combinations were found $\left({ }^{*} \mathrm{p}<0.05\right.$ and $\left.{ }^{* *} \mathrm{p}<0.01\right)$. 

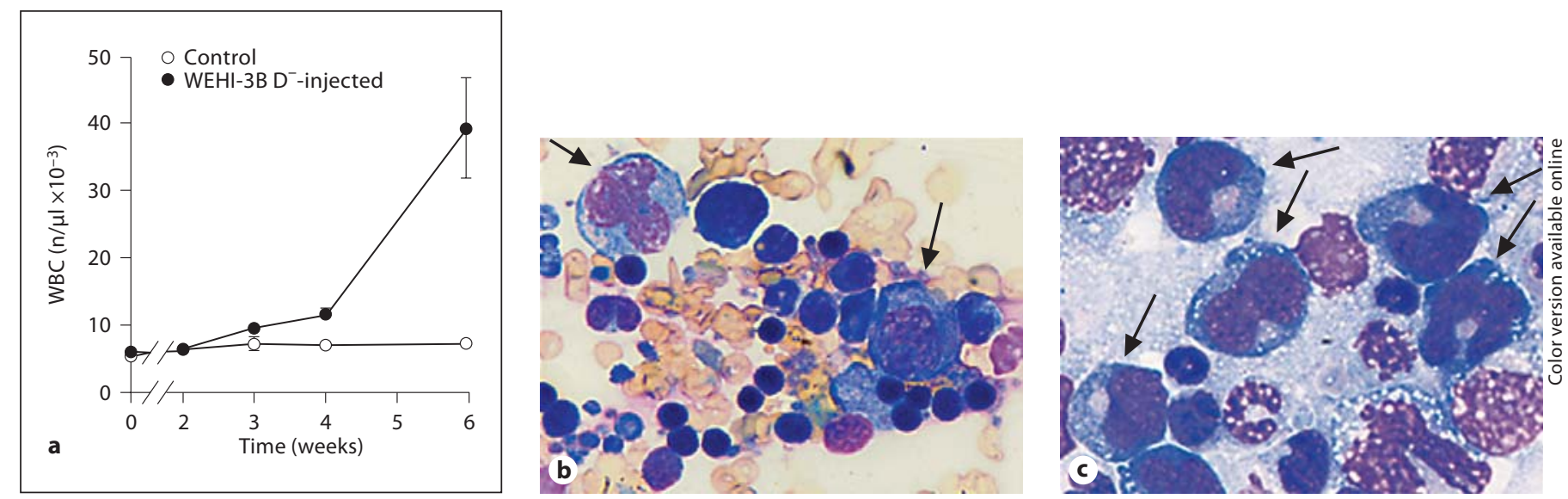

Fig. 6. Systemic leukemia induced by intravenous inoculation of WEHI cells in syngeneic Balb/c mice. Six animals were injected with $2 \times 10^{6} \mathrm{WEHI}$ cells in the lateral tail vein and monitored for 6 weeks. a WBC counts in retro-orbital blood samples. b-d Wright-Giemsa-stained smears of peripheral blood (b) and bone marrow (c) were taken from a sacrificed moribund mouse, 41 days after cell inoculation. Large blast cells are indicated by arrows. Leukemic blasts clustered in the bone marrow (d) and cultured WEHI cells $(\mathbf{e})$ display similar size and morphology. $\times 1.000$.
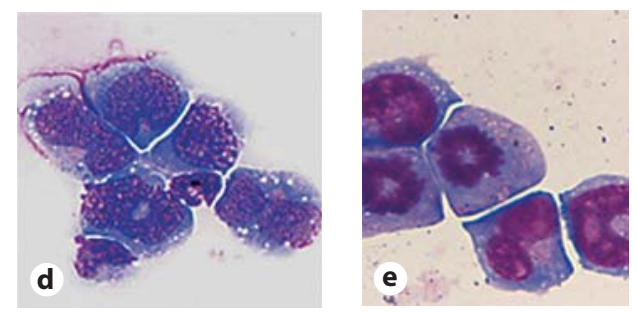

Table 1. Cooperative effects of 19-nor-Gemini (19-nor) and rosemary extract (RE) on the survival of leukemia-bearing animals

\begin{tabular}{llllrl}
\hline $\begin{array}{l}\text { Experiment } \\
\text { No. }\end{array}$ & \multicolumn{5}{l}{ Median survival time, days } \\
\cline { 2 - 6 } & control & $\begin{array}{l}19-\text {-nor } \\
(0.1 \mu \mathrm{g})\end{array}$ & $\begin{array}{l}\mathrm{RE} \\
(4 \%)\end{array}$ & \multicolumn{1}{l}{$\begin{array}{l}19-\text {-nor }+ \\
\mathrm{RE}^{1}\end{array}$} & p value \\
\hline $1(\mathrm{n}=6)$ & 47 & 52.5 & 54 & $67(42.5)$ & 0.0180 \\
$2(\mathrm{n}=6)$ & 40.5 & 51 & 46.5 & $73.5(81.5)$ & 0.0365 \\
$3(\mathrm{n}=10)$ & 39 & 43 & 43.5 & $59(51.3)$ & 0.0104 \\
\hline
\end{tabular}

Median survival times were determined in three experiments by the Kaplan-Meier analysis (fig. 7a). $n=$ Number of mice per treatment group. Significant differences in the median survival times between the 19-nor + RE treatment group and the untreated control group (log-rank test) are shown.

${ }^{1}$ The percent increase in the animal life span in the 19-nor + $\mathrm{RE}$ treatment group compared with untreated control mice is indicated in parentheses.

and were sacrificed due to progressively poor conditions, such as hind limb paralysis, lateral recumbency and/or lethargy. The median survival of leukemia-bearing mice was $43.0 \pm 1.2$ days $(n=22)$. AML was diagnosed by leukocytosis ( $\geq 10,000 \mathrm{WBC} / \mu \mathrm{l}$; fig. $6 \mathrm{a})$ and the appearance of large proportions of blast-like cells in both peripheral blood (fig. 6b) and bone marrow (fig. 6c). The blast cells detected in leukemic specimens (fig. 6b, c) were clearly distinguished from host WBCs by the size and morphology but were similar to WEHI cells growing in liquid culture (compare fig. $6 \mathrm{~d}$, e). Necropsy revealed the enlargement of the spleen and frequent leukemia cell deposits in lymphatic nodes, liver and ovary (data not shown).

\section{Combined Antileukemic Effects of 19-nor-Gemini and Rosemary Extract}

To determine the antileukemic activity of 19-norGemini and rosemary extract, alone and in combination, three independent in vivo experiments were performed in groups of 6-10 animals (fig. 7a; table 1). Mice inoculated intravenously with WEHI cells were treated with 0.1 $\mu \mathrm{g}$ 19-nor-Gemini, 4\% (w/w) rosemary extract or their combination, as described. To approximate the treatment protocol to the clinical situation, all treatments started 7 days after cell inoculation in order to ensure homing of the leukemic cells to the bone marrow prior to interventions. At this time point, the WEHI blast cells represented $2-5 \%$ of the total nucleated bone marrow cells, as detected on Wright-Giemsa-stained smears (data not shown). As demonstrated in figure 7a, treatment with 19nor-Gemini or rosemary extract alone had only a slight effect on median survival compared with control mice. 


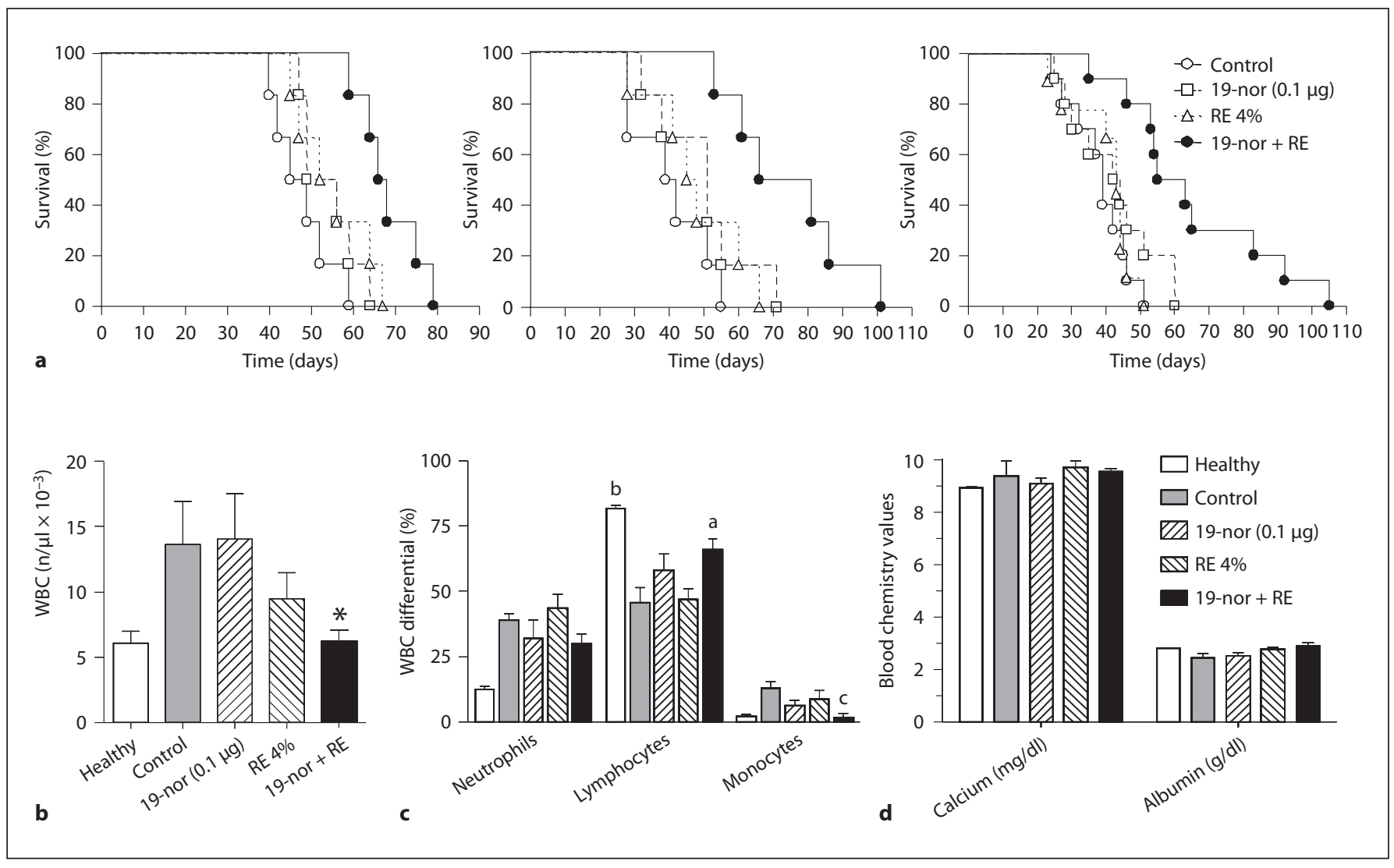

Fig. 7. Combined antileukemic effect of rosemary extract (RE) and 19-nor-Gemini (19-nor) in a mouse model of systemic AML. a Balb/c mice were inoculated with $2 \times 10^{6} \mathrm{WEHI}$ cells i.v. and treated with 19 -nor-Gemini $(0.1 \mu \mathrm{g})$ or rosemary extract $(4 \% \mathrm{w} / \mathrm{w}$, mixed with food) either alone or in combination, or vehicle $(0.05 \%$ ethanol, i.p.). Groups of 6 (experiments 1 and 2) and 10 (experiment 3) mice were used. Animal survival was estimated by the Kaplan-Meier analysis. WBC number (b) and differential count (c) as well as blood chemistry parameters (d) were determined on day 38 in retro-orbital blood samples of 6 mice randomly selected from each treatment group (experiment 3). Means \pm SE. $\mathbf{b}^{*} \mathrm{p}<$ 0.05 vs. untreated control. $\mathrm{c}^{\mathrm{a}} \mathrm{p}<0.05$ and ${ }^{\mathrm{b}} \mathrm{p}<0.01$ : statistically significant differences in neutrophil/lymphocyte ratios obtained for combination-treated mice $(0.44 \pm 0.05)$ vs. untreated controls $(0.85 \pm 0.11)$, and healthy animals $(0.15 \pm 0.02)$ vs. untreated controls $(0.85 \pm 0.11) ;{ }^{\mathrm{c}} \mathrm{p}<0.05$ : vs. untreated control.
However, the combined treatment markedly (by $42.5-$ 81.5\%) extended the animal life span in a synergistic manner (see median survival data in table 1). This effect was associated with the improvement in both the WBC and differential counts. Thus, when measured 38 days after WEHI cell inoculation (experiment 3 ), significantly lower total WBC numbers were detected in mice receiving combined treatment compared with the control mice (fig. 7b). Further, the WBC differential count of control mice and those treated with single agents displayed a relatively large myeloid component with minimal morphologic dyspoiesis (fig. 7c), consistent with mouse myeloproliferative conditions, e.g. nonlymphoid (myeloid) leukemias [30]. However, the combined treatment significantly decreased neutrophil/lymphocyte ratios and monocyte counts (fig. 7c). Importantly, the above WBC parameters in the combination group were close to those determined in the healthy mice which did not receive either leukemic cell injections or any other treatment (fig. 7b, c). While synergizing with 19-nor-Gemini in the antileukemic action, rosemary extract did not increase the calcemic effect of the deltanoid (fig. 7d). Serum albumin levels in control or treated mice were not significantly different from those in the intact healthy animals (fig. 7d), which indicates the absence of liver toxicity in these experiments. Collectively, these results, along with our previous data obtained in a leukemic tumor model [14], strongly suggest that combinations of rosemary antioxidants and deltanoids may be considered as a promising effective and low-toxic therapy of AML. 


\section{Discussion}

Here we characterized the combined in vitro and in vivo antileukemic activity of the low-calcemic deltanoid, 19-nor-Gemini, and rosemary phenolic preparations. As determined in the in vitro assays, this deltanoid demonstrated a much greater differentiation capacity and antiproliferative effect in WEHI cells compared with its parent compounds Gemini and $1,25 \mathrm{D}_{3}$ (fig. $2 \mathrm{a}, \mathrm{b}$ ), and strongly cooperated in these activities with both purified carnosic acid and carnosic acid-rich rosemary extract. Thus, being moderately $(\sim 1.5$-fold $)$ less calcemic but about 10 -fold more potent than $1,25 \mathrm{D}_{3}$, this analogue would exert superior anticancer activity in clinical situations, especially in combination with other agents.

We have recently shown that another low-calcemic deltanoid (Ro25-4020) and rosemary extract cooperatively inhibit the growth of WEHI cell-derived leukemic tumors in Balb/c mice [14]. Although such tumor is reminiscent of chloroma, a human solid leukemic tumor, it does not fully model the disseminated AML. Thus, here we translated these findings to a more clinically relevant mouse model of systemic AML. Our data show for the first time that rosemary extract and 19-nor-Gemini synergistically prolonged the survival of leukemia-bearing $\mathrm{Balb} / \mathrm{c}$ mice. This action was consistent with significantly improved hematologic parameters, such as WBC count and the neutrophil/lymphocyte ratio, in the combination-treated animals. It should be noted, however, that while markedly delaying the development of systemic leukemia, the 19-nor-Gemini/rosemary extract combination did not completely eliminate the pathologic process, so that leukemia-bearing mice eventually died of AML. Therefore, there is an ultimate need for the further optimization of the treatment protocol and/or utilization of different/novel combinations of deltanoids and a variety of plant polyphenols.

The molecular mechanism of the synergistic activity of $1,25 \mathrm{D}_{3}$ and plant polyphenolic antioxidants against myeloid leukemia cells has been extensively studied in our and other laboratories [7, 18-23] (see also Danilenko and Studzinski [31] for a recent review). We have shown that in human HL60 cells, $1,25 \mathrm{D}_{3}$ and carnosic acid cooperate in an antioxidant effect and elevation of glutathione levels, whereas glutathione depletion markedly suppressed the differentiation effects of both $1,25 \mathrm{D}_{3}$ alone and, particularly, its combination with the polyphenol [21]. The current study in murine AML cells further supports these findings by demonstrating that both rosemary agents and deltanoids have antioxidant actions and can cooperate in at least some of the redox-regulating cellular pathways, e.g. the induction of the antioxidant enzyme NADP(H)-quinone oxireductase.

The nature of the link between the antioxidant effect of rosemary agents and their ability to sensitize leukemic cells to deltanoids still needs further elucidation. However, recent findings suggest that generation of intracellular reducing conditions promotes cell differentiation in leukemia, possibly via modulation of certain redox-sensitive signal transduction and transcription systems, such as signaling kinase pathways and the transcription factors nuclear factor $\kappa \mathrm{B}(\mathrm{NF \kappa B})$ and activating protein-1 (AP-1) $[32,33]$. For instance, potentiation of deltanoidinduced HL60 cell differentiation by the polyphenolic antioxidant curcumin was associated with inhibition of NFкB [18]. Also, different plant antioxidants which are capable of reducing NFKB activity were found to sensitize cancer cells to apoptosis due to inhibition of NFкB-dependent transcription of 'survival genes' that provide resistance to apoptosis $[34,35]$. We have found that polyphenols potentiate $1,25 \mathrm{D}_{3}$-induced activation of mitogen-activated protein kinase (extracellular signal-regulated kinase and c-Jun N-terminal kinase) pathways, which target AP-1 [20, 21]. Further, both AP-1 binding to its cognate DNA response element and transcriptional activity were markedly augmented by $1,25 \mathrm{D}_{3}$-polyphenol combinations $[20,21]$. In addition, we have recently reported that competitive inhibition of AP-1 by a doublestranded decoy oligodeoxynucleotide markedly decreased the differentiation response of HL60 cells to $1,25 \mathrm{D}_{3}[36]$.

Up-regulation of AP-1 [37] and another transcription factor, Wilms' tumor suppressor 1 (WT1) [38], in solid tumor cells has been shown to elevate the expression of vitamin $\mathrm{D}$ receptor (VDR) and, thereby, to enhance the antiproliferative effect of $1,25 \mathrm{D}_{3}$. In leukemia cells, elevation of VDR levels by $1,25 \mathrm{D}_{3}$ and carnosic acid [22] correlated with the activation of AP-1 [20,21], whereas WT1 was shown to be down-regulated by $1,25 \mathrm{D}_{3}$ and other inducers of myeloid differentiation [39] as well as by curcumin [40]. Therefore, the precise roles of AP-1, WT1 and VDR in the enhanced antileukemic effects of $1,25 \mathrm{D}_{3}$-polyphenol combinations remain to be elucidated.

Taken together, the results presented here clearly demonstrate that a vitamin $\mathrm{D}$ derivative and a plant polyphenolic preparation can strongly cooperate against systemic AML. Therefore, at least some polyphenols with differentiation-enhancing activity, which also possess antitumor properties of their own [41-43], can be em- 
ployed in the deltanoid-based, low-toxic combination differentiation therapy of at least some types of myeloid leukemias. Further, both deltanoids [44] and various phytochemicals [45] have been shown to suppress carcinogenesis and, thus, their cooperation may account for the chemopreventive effect of vitamin D and polyphenolrich diets.

Syngeneic mouse models are widely employed in translational leukemia studies [46, 47]. Moreover, mouse AML has already been shown to respond to deltanoid therapy in syngeneic models $[14,48-50]$. The attractive advantages of these models include their relatively low costs and the use of mice with non-compromised immune system. We have demonstrated that murine and human leukemic cells respond to combined deltanoidpolyphenol treatments in a very similar manner [14], which suggests that our current study would provide useful information for potential clinical applications of such combinations.

\section{Acknowledgments}

This work was supported by grants RO1-CA117942-01 from the National Cancer Institutes and 05A022 from the American Institute for Cancer Research (both to G.P.S. and M.D.), the Israel Science Foundation grant 778/07 (to M.D. and Y.S.) and NIH grant RO1-CA 44722-18 (to G.P.S). We thank Ms. Orly Priev and Ms. Elena Kirillov for their excellent technical assistance in cell culture assays and hematological tests, respectively. We also thank Dr. A. Sartorelli (Yale University) and Dr. Zohar Nir (LycoRed Natural Products Industries) for generous donation of WEHI cells and rosemary extract, respectively.

\section{References}

1 Estey E, Dohner H: Acute myeloid leukaemia. Lancet 2006;368:1894-1907.

-2 Eelen G, Gysemans C, Verlinden L, Vanoirbeek E, De Clercq P, Van Haver D, Mathieu C, Bouillon R, Verstuyf A: Mechanism and potential of the growth-inhibitory actions of vitamin D and analogs. Curr Med Chem 2007;14:1893-1910.

3 Deeb KK, Trump DL, Johnson CS: Vitamin D signalling pathways in cancer: potential for anticancer therapeutics. Nat Rev Cancer 2007;7:684-700.

- 4 Trump DL, Muindi J, Fakih M, Yu WD, Johnson CS: Vitamin D compounds: clinical development as cancer therapy and prevention agents. Anticancer Res 2006;26:25512556.

5 Hisatake J, Kubota T, Hisatake Y, Uskokovic M, Tomoyasu S, Koeffler HP: 5,6-trans-16ene-vitamin $\mathrm{D}_{3}$ : a new class of potent inhibitors of proliferation of prostate, breast, and myeloid leukemic cells. Cancer Res 1999;59: 4023-4029.

6 Alagbala AA, Johnson CS, Trump DL, Posner GH, Foster BA: Antitumor effects of two less-calcemic vitamin D analogs (paricalcitol and QW-1624F2-2) in squamous cell carcinoma cells. Oncology 2006;70:483-492.

7 Zhang J, Posner GH, Danilenko M, Studzinski GP: Differentiation-inducing potency of the seco-steroid JK-1624F2-2 can be increased by combination with an antioxidant and a $38 \mathrm{MAPK}$ inhibitor which upregulates the JNK pathway. J Steroid Biochem Mol Biol 2007;105:140-149.
8 Maehr H, Uskokovic M, Adorini L, Penna G, Mariani R, Panina P, Passini N, Bono E, Perego S, Biffi M, Holick M, Spina C, Suh N: Calcitriol derivatives with two different side chains at C-20. III. An epimeric pair of the Gemini family with unprecedented antiproliferative effects on tumor cells and renin mRNA expression inhibition. J Steroid Biochem Mol Biol 2007;103:277-281.

-9 Narvaez CJ, Byrne BM, Romu S, Valrance $\mathrm{M}$, Welsh J: Induction of apoptosis by 1,25dihydroxyvitamin $\mathrm{D}_{3}$ in MCF-7 vitamin $\mathrm{D}_{3}$-resistant variant can be sensitized by TPA. J Steroid Biochem Mol Biol 2003;84: 199-209.

10 Swami S, Krishnan AV, Peehl DM, Feldman D: Genistein potentiates the growth inhibitory effects of 1,25-dihydroxyvitamin $\mathrm{D}_{3}$ in DU145 human prostate cancer cells: role of the direct inhibition of CYP24 enzyme activity. Mol Cell Endocrinol 2005;241:49-61.

11 Kumagai T, Shih LY, Hughes SV, Desmond JC, O’Kelly J, Hewison M, Koeffler HP: 19Nor-1,25(OH) ${ }_{2} \mathrm{D}_{2}$ (a novel, noncalcemic vitamin $\mathrm{D}$ analogue), combined with arsenic trioxide, has potent antitumor activity against myeloid leukemia. Cancer Res 2005; 65:2488-2497.

12 Koren R, Wacksberg S, Weitsman GE, Ravid A: Calcitriol sensitizes colon cancer cells to $\mathrm{H}_{2} \mathrm{O}_{2}$-induced cytotoxicity while inhibiting caspase activation. J Steroid Biochem Mol Biol 2006;101:151-160.

13 Young MR, Lathers DM: Combination docetaxel plus vitamin $\mathrm{D}_{3}$ as an immune therapy in animals bearing squamous cell carcinomas. Otolaryngol Head Neck Surg 2005;133:611-618.
Sharabani H, Izumchenko E, Wang Q, Kreinin R, Steiner M, Barvish Z, Kafka M, Sharoni Y, Levy J, Uskokovic M, Studzinski GP, Danilenko M: Cooperative antitumor effects of vitamin $\mathrm{D}_{3}$ derivatives and rosemary preparations in a mouse model of myeloid leukemia. Int J Cancer 2006;118:30123021.

15 Flaig TW, Barqawi A, Miller G, Kane M, Zeng C, Crawford ED, Glode LM: A phase II trial of dexamethasone, vitamin $\mathrm{D}$, and carboplatin in patients with hormone-refractory prostate cancer. Cancer 2006; 107:266274.

16 Trump DL, Potter DM, Muindi J, Brufsky A, Johnson CS: Phase II trial of high-dose, intermittent calcitriol (1,25 dihydroxyvitamin $\mathrm{D}_{3}$ ) and dexamethasone in androgen-independent prostate cancer. Cancer 2006;106: 2136-2142.

17 Yamada K, Mizusawa M, Harima A, Kajiwara K, Hamaki T, Hoshi K, Kozai Y, Kodo $\mathrm{H}$ : Induction of remission of relapsed acute myeloid leukemia after unrelated donor cord blood transplantation by concomitant lowdose cytarabine and calcitriol in adults. Eur J Haematol 2006;77:345-348.

18 Sokoloski JA, Shyam K, Sartorelli AC: Induction of the differentiation of HL-60 promyelocytic leukemia cells by curcumin in combination with low levels of vitamin $\mathrm{D}_{3}$. Oncol Res 1997;9:31-39.

-19 Kang SN, Lee MH, Kim KM, Cho D, Kim TS: Induction of human promyelocytic leukemia HL-60 cell differentiation into monocytes by silibinin: involvement of protein kinase C. Biochem Pharmacol 2001;61:14871495. 
20 Wang Q, Salman H, Danilenko M, Studzinski GP: Cooperation between antioxidants and 1,25-dihydroxyvitamin $\mathrm{D}_{3}$ in induction of leukemia HL60 cell differentiation through the JNK/AP-1/Egr-1 pathway. J Cell Physiol 2005;204:964-974.

-21 Danilenko M, Wang Q, Wang X, Levy J, Sharoni Y, Studzinski GP: Carnosic acid potentiates the antioxidant and prodifferentiation effects of $1 \alpha, 25$-dihydroxyvitamin $\mathrm{D}_{3}$ in leukemia cells but does not promote elevation of basal levels of intracellular calcium. Cancer Res 2003;63:1325-1332.

22 Danilenko M, Wang X, Studzinski GP: Carnosic acid and promotion of monocytic differentiation of HL60-G cells initiated by other agents. J Natl Cancer Inst 2001;93: 1224-1233.

-23 Steiner M, Priel I, Giat J, Levy J, Sharoni Y, Danilenko M: Carnosic acid inhibits proliferation and augments differentiation of human leukemic cells induced by 1,25-dihydroxyvitamin $\mathrm{D}_{3}$ and retinoic acid. Nutr Cancer 2001;41:135-144.

-24 Bury Y, Herdick M, Uskokovic MR, Carlberg C: Gene regulatory potential of $1 \alpha, 25$-dihydroxyvitamin $\mathrm{D}_{3}$ analogues with two side chains. J Cell Biochem Suppl 2001;(suppl 36):179-190.

-25 Shiohara M, Uskokovic M, Hisatake J, Hisatake Y, Koike K, Komiyama A, Koeffler HP: 24-Oxo metabolites of vitamin $\mathrm{D}_{3}$ analogues: disassociation of their prominent antileukemic effects from their lack of calcium modulation. Cancer Res 2001;61:3361-3368.

26 Hosmer DW, Lemeshow S: Applied Survival Analysis: Regression Modeling of Time to Event Data. New York, Wiley, 1999.

-27 Moreno S, Scheyer T, Romano CS, Vojnov AA: Antioxidant and antimicrobial activities of rosemary extracts linked to their polyphenol composition. Free Radic Res 2006;40: 223-231.

28 Chen C, Kong AN: Dietary cancer-chemopreventive compounds: from signaling and gene expression to pharmacological effects. Trends Pharmacol Sci 2005;26:318-326.

29 Berdel WE, Okamoto S, Danhauser-Riedl S, Hong CI, Winton EF, West CR, Rastetter J, Vogler WR: Therapeutic activity of 1- $\beta$-Darabinofuranosylcytosine conjugates of lipids in WEHI-3B leukemia in mice. Exp Hematol 1989;17:364-367.
30 Kogan SC, Ward JM, Anver MR, Berman JJ, Brayton C, Cardiff RD, Carter JS, de Coronado S, Downing JR, Fredrickson TN, Haines DC, Harris AW, Harris NL, Hiai H, Jaffe ES, MacLennan IC, Pandolfi PP, Pattengale PK, Perkins AS, Simpson RM, Tuttle MS, Wong JF, Morse HC 3rd: Bethesda proposals for classification of nonlymphoid hematopoietic neoplasms in mice. Blood 2002; 100:238-245.

31 Danilenko M, Studzinski GP: Enhancement by other compounds of the anti-cancer activity of vitamin $\mathrm{D}_{3}$ and its analogs. Exp Cell Res 2004;298:339-358.

32 Gius D, Botero A, Shah S, Curry HA: Intracellular oxidation/reduction status in the regulation of transcription factors NF- $\mathrm{KB}$ and AP-1. Toxicol Lett 1999;106:93-106.

33 Giles GI: The redox regulation of thiol dependent signaling pathways in cancer. Curr Pharm Des 2006;12:4427-4443.

- 34 Estrov Z, Shishodia S, Faderl S, Harris D, Van Q, Kantarjian HM, Talpaz M, Aggarwal BB: Resveratrol blocks interleukin-1 $\beta$-induced activation of the nuclear transcription factor NF- $\kappa B$, inhibits proliferation, causes $\mathrm{S}$-phase arrest, and induces apoptosis of acute myeloid leukemia cells. Blood 2003; 102:987-995.

35 Tamatani T, Azuma M, Motegi K, Takamaru N, Kawashima Y, Bando T: Cepharanthinenhanced radiosensitivity through the inhibition of radiation-induced nuclear factorkappaB activity in human oral squamous cell carcinoma cells. Int J Oncol 2007;31:761768.

36 Wang X, Studzinski GP: The requirement for and changing composition of the activating protein-1 transcription factor during differentiation of human leukemia HL60 cells induced by 1,25-dihydroxyvitamin $\mathrm{D}_{3}$. Cancer Res 2006;66:4402-4409.

-37 Qi X, Pramanik R, Wang J, Schultz RM, Maitra RK, Han J, DeLuca HF, Chen G: The p38 and JNK pathways cooperate to trans-activate vitamin D receptor via c-Jun/AP-1 and sensitize human breast cancer cells to vitamin $\mathrm{D}_{3}$-induced growth inhibition. J Biol Chem 2002;277:25884-25892.

38 Maurer U, Jehan F, Englert C, Hubinger G, Weidmann E, DeLuca HF, Bergmann L: The Wilms' tumor gene product (WT1) modulates the response to 1,25-dihydroxyvitamin $\mathrm{D}_{3}$ by induction of the vitamin $\mathrm{D}$ receptor. J Biol Chem 2001;276:3727-3732.

- 39 Sekiya M, Adachi M, Hinoda Y, Imai K, Yachi A: Downregulation of Wilms' tumor gene (wt1) during myelomonocytic differentiation in HL60 cells. Blood 1994;83:18761882 .
40 Anuchapreeda S, Limtrakul P, Thanarattanakorn P, Sittipreechacharn S, Chanarat P: Inhibitory effect of curcumin on WT1 gene expression in patient leukemic cells. Arch Pharm Res 2006;29:80-87.

41 Singletary K, MacDonald C, Wallig M: Inhibition by rosemary and carnosol of 7,12-dim ethylbenz(a)anthracene (DMBA)-induced rat mammary tumorigenesis and in vivo DMBA-DNA adduct formation. Cancer Lett 1996;104:43-48.

42 Singh RP, Deep G, Chittezhath M, Kaur M, Dwyer-Nield LD, Malkinson AM, Agarwal R: Effect of silibinin on the growth and progression of primary lung tumors in mice. J Natl Cancer Inst 2006;98:846-855.

-43 Lin YG, Kunnumakkara AB, Nair A, Merritt WM, Han LY, Armaiz-Pena GN, Kamat AA, Spannuth WA, Gershenson DM, Lutgendorf SK, Aggarwal BB, Sood AK: Curcumin inhibits tumor growth and angiogenesis in ovarian carcinoma by targeting the nuclear factor-kappaB pathway. Clin Cancer Res 2007;13:3423-3430.

44 Agoston ES, Hatcher MA, Kensler TW, Posner GH: Vitamin D analogs as anti-carcinogenic agents. Anticancer Agents Med Chem 2006;6:53-71.

45 Lambert JD, Hong J, Yang GY, Liao J, Yang CS: Inhibition of carcinogenesis by polyphenols: evidence from laboratory investigations. Am J Clin Nutr 2005;81:284S-291S.

- 46 Hoepfl J, Miething C, Grundler R, Gotze KS, Peschel C, Duyster J: Effects of imatinib on bone marrow engraftment in syngeneic mice. Leukemia 2002;16:1584-1588.

-47 Williams RT, Roussel MF, Sherr CJ: Arf gene loss enhances oncogenicity and limits imatinib response in mouse models of Bcr-Ablinduced acute lymphoblastic leukemia. Proc Natl Acad Sci USA 2006;103:6688-6693.

48 Honma Y, Hozumi M, Abe E, Konno K, Fukushima M, Hata S, Nishii Y, DeLuca HF, Suda T: $1 \alpha, 25$-Dihydroxyvitamin $\mathrm{D}_{3}$ and $1 \alpha$ hydroxyvitamin $\mathrm{D}_{3}$ prolong survival time of mice inoculated with myeloid leukemia cells. Proc Natl Acad Sci USA 1983;80:201-204.

49 Kasukabe T, Honma Y, Hozumi M, Suda T, Nishii Y: Control of proliferating potential of myeloid leukemia cells during long-term treatment with vitamin $\mathrm{D}_{3}$ analogues and other differentiation inducers in combination with antileukemic drugs: in vitro and in vivo studies. Cancer Res 1987;47:567-572.

50 Zhou JY, Norman AW, Chen DL, Sun GW, Uskokovic M, Koeffler HP: 1,25-Dihydroxy16-ene-23-yne-vitamin $\mathrm{D}_{3}$ prolongs survival time of leukemic mice. Proc Natl Acad Sci USA 1990;87:3929-3932. 